\title{
Role of Internet Technology on Marketing of Women led Products. Case of Jubilee Market, Kisumu, Kenya
}

\author{
${ }^{1}$ Kwama Leonard Ogweno, ${ }^{2}$ Ondiek Alfred Collins, ${ }^{3}$ Mzee Rajab Mohammed \\ ${ }^{l}$ KCA University, Faculty of Computing and Information Management, P.O Box 3207- 40100 Kisumu, Kenya; \\ ${ }^{2}$ Maseno University, School of Planning and Architecture, Department of Urban and regional planning
}

Private Bag, Maseno, Kenya:

\begin{abstract}
Executive Summary: Information and data are the tools needed to navigate today are increasingly complex and globally linked marketplace. Productivity is an important economic factor which has a key role in evaluating the economic growth. It is identified as the foundation for economic prosperity, a prerequisite for national development and also an important indicator of organizational competitiveness (Dedrick et al., 2003). Most countries, particularly rural populations, have largely been left out of the information revolution, given the absence of basic infrastructure, high costs of Internet Technology deployment, unfamiliarity with Internet Technology, dominance of the English language in Internet content and indeed - lack of demonstrated benefit from Internet Technology to address ground-level development challenges. These barriers pose even greater problems for women, who lack opportunities for training in computer skills. The general objective of the study was to assess the role of internet technologies on marketing of women led CBO products. Specifically, to examine the use of internet technology on marketing of women led products, to establish the impediments towards the use of internet technology on marketing of Women led products, to investigate the achievements of internet technology marketing in enhancing performance of women-led projects. . It was a descriptive survey study. The target population comprised all the women led CBO's registered within Kisumu Municipality and have their products at jubilee marketing, the respondents being chief executive officers and other members of the CBOs' who were selected randomly. Primary data was collected through interview schedules administered to members, and semi structured questionnaire administered to group members. Group documents were used to collect secondary data. Data was analyzed using both quantitative and qualitative methods. Qualitative data was used to analyze content analysis.
\end{abstract}

Key words; internet technology, women, productivity, performance

\section{Introduction}

In recent years, there has been a growth in direct marketing to consumers by small- and medium-size producers as a popular marketing practice in the Africa. More farmers are trying to meet the growing demand for local produce as this is an important source of revenue for them (Thilmany et al., 2006). Internet Technologies (ITs) generally refer to an expanding assembly of technologies that are used to handle information and aid communication. These include media for collection, storage, processing, transmission and presentation of information in any format (i.e., voice, data, text and image), computers, the Internet itself, email, video, digital cameras etc. The advent of personal computers, the Internet and mobile telephone during the last two decades has provided a much wider choice in collection, storage, processing, transmission and presentation of information in multiple formats to meet the diverse requirement and skills of people.

Farmers have always had to make decisions about what to plant, when to plant and where to sell. In the past, however, such decisions were often not very complicated. They often planted the crops that their neighbors planted, at the same time as their neighbors planted and sold to the buyer or buyers that their neighbors sold to. The situation is now changing. Many farmers now find themselves having to be market oriented and having to make individual decisions about what, when and how to market. Some of the reasons for these changes include: price setting arrangements, improved cultivation techniques, increased demand caused by greater urbanization, increased opportunity for international trade in perishable produce (Demiryürek et al. 2008). Specifically, the information requirements of farmers, the structure of the organizations involved in these activities are issues that need to be explored. (Rogers 1995; Ramirez 1997; Garforth 2001; Leeuwis 2004) this study seeks to identify the situation at Jubilee market, i.e. ways in which farmers access market information, how they utilize the information received and the challenges they face in marketing of their produce, it also looks at the best way jubilee market owners can use IT in marketing their products. Traditional media and new ITs have played a major role in diffusing information to rural communities, and have much more potential. Despite the emphasis placed on ITs, many IT initiatives have stalled in Developing Countries (DC)s. In short, the question of how community-based IT initiatives can survive financially, that is be sustainable in the longer term, has grown in significance (Gurstein, 2001). In this paper, the role of ITs in the marketing of women led products from the 
communities is initially considered and some of the reasons for the failure of IT initiatives are then explored, finally the critique and way forward are discussed. This discussion leads us to ask whether there are more effective models of the implementation of ITs and their role in regional development.

Based on a review of the literature in this field and on action research conducted in within Kisumu municipality, it is proposed that regional IT initiatives need to:

(i) achieve clarity in specifying sustainability goals to check on how the tools will be maintained by both the users and the providers;

(ii) Build on local industry strengths and learn from global experiences whilst building on local assets thereby ensuring both sides of the divide is at per with the technological know-how;

(iii) Find innovative business models to capitalise on new ICT opportunities for content and applications thereby making the tool more useful and productive by promoting creativity;

(iv) Ensure community involvement in deciding, planning and evaluating projects that they feel are beneficial to the locality and;

(v) Adopt a learning approach through cycles of evaluation based on action research which is very important for the users of the technology to understand its operations and diversify in opportunities' that come with it.

This study focuses on the role of Internet Technology on marketing of women led products among CBOs that are run by women at the Jubilee Market in Kisumu Municipality. The Kisumu municipal Market was established in 1935. It is a farmers' market, with over 300 stalls stocking all sorts of items including Turkana baskets, pots, fruits, cereals and the famous fish market adjacent to it. It borders the Kisumu Bus Park which is a transport hub for all travelers from the surrounding towns and villages. Kisumu Municipal Market is a real local business establishment located at Gumbi Road, Kisumu, Kenya. The population for the study targeted 128 traders dealing in a variety of agricultural produce who were purposively sampled as the subject of the study.

\section{A REVIEW OF INTERNET TECHNOLOGY ADOPTION LITERATURE Benefits of Internet technology}

The benefits of ITs reach even those who do not themselves have first-hand access to them. Through ITs, for example, a doctor in a rural village can get up-to-date information regarding certain diseases and can use that information to advice and treat patients; an agricultural extension worker can learn new technologies, rainfall forecasts, commodity prices, etc and use that information to advice farmers in rural villages; etc. The importance of ITs in development process was long recognized and access to ITs was even made one of the targets of the Millennium Development Goal No. 8 (MDG 8), which emphasizes the benefits of new technologies, especially ITs in the fight against poverty. "With 10 percent increase in high-speed internet connections, economic growth increases by 1.3 percent" observed the recent World Bank report on Information and Communication for Development (World Bank, 2009). The same report also observed "connectivity whether the Internet or mobile phones -- is increasingly bringing market information, financial services, and health services to remote areas, and is helping to change people's lives in unprecedented ways".

This observation is shared by Kuppusamy and Santharappy (2005) who demonstrates in a rigorous study that ICT investment is the most significant factor that drove economic growth in Malaysia over the period 19752002. ICT investment in Malaysia was able to generate substantial economic benefits in terms of higher productivity and economic growth because of strategic efforts by the government of that country. The study notes that "...heavy industrialization policies and strategic efforts by the government have induced high ICT capital investment over the years" (p. 63). The study concludes that "the development of modern, technically efficient and cost-effective ICT infrastructure is of critical importance to the establishment of effective communication services in Malaysia" (p. 163). The authors recommend the education sector as key to the success of an effective and efficient ICT implementation in Malaysia as it helped in training of the people who were directly involved in the use of internet technology.

Senegal is reported to be one of the few countries in Francophone West Africa to recognize the importance of ICT as a tool for achieving "Education For All" goals which has made most organizations in Senegal to go global. Wagner et al (2005) point out that "In Senegal, for example, one of the more economically advanced Francophone countries in this field, parents of pupils do not hesitate to pay the costs related to connection of schools and allowing their children access computer rooms; moreover, even school teachers often oppose going to work in schools with insufficient ICT support" (p. 6). This country, which is much smaller than DRC and has fewer economic resources than DRC, understands that "ICT is good for a school's overall 'health"' (Wagner et al, 2005, p.6). It is worth noting that Senegal has adopted an ICT4E plan while DRC has not yet contemplated even remotely investing in ICT. In secondary schools in Senegal, "ICT already serves as a complement to or has even been integrated into the traditional curriculum" (Wagner et al, 2005, p.6). The best example of ICT success story comes from Korea. ICT capital contributed 16.3 percent to the output growth of Korea between 1971 and 2000. ICT investment has a strong positive effect on the growth of labor productivity in the long run (Kuppusamy and Santharappy, 2005, p. 151). This great result could not have been possible 
without a real commitment and serious strategic planning from the government of Korea. Naturally, it appears that countries that invest strategically in ICT reap significant returns from their investment. ICT can also be used to strengthen democracy development, as is the case in South Africa (Torero and Braun, 2006, p. 5).

\section{Internet Market environments}

Current trends in the market environment, such as shrinkage of markets, increase of competition, technology turbulence, and diffusion of the IT through the organizations, preempt structural changes in the organizations and their marketing channels. These trends call for increased collaboration among organizations that leads to increased outsourcing activities, transformations in the value chains of the organizations and of their distribution channels, and the formation of new network organizational structures. Thus, although the Internet has been the favorable theme for numerous researchers and scholars during the last decade, there is still a lack of systematic practical evidence regarding the role of the Internet vis-à-vis the marketing activities and performance of business organizations especially on the best ways that internet can be used in achieving organizational goals, and the drawback has been felt mostly in women led businesses. This research addresses these issues which include; looking at the relationship between women, internet technology and marketing, we attempt to investigate how the use of the Internet technology affects their marketing efforts and performance and finally looks at the achievements of internet technology to the marketing of products of which in this case is more of agricultural produce.

\section{Women and Internet Technology}

Huyer (1997), discussed issues of access, the benefit to African women of using Internet Technology, and their role in the production and dissemination of information. The author discusses how to empower African women through Internet Technology and the barriers to their full use of these technologies, the first being the high rates of illiteracy. The work has five case studies (four from South Africa and one from Uganda) to explain the importance of developing 'women-friendly Internet Technology systems'. According to the author, one of the major findings was that the type of information accessed by women is an important consideration. It is recommended that Internet Technology be located in local institutions to which women have open and equal access, such as health centres, women's NGOs and churches. The purpose of the project was to identify women's groups that were able to make successful electronic connections and to follow up those that were experiencing difficulties. It was also intended to integrate groups working on the same topic through the networks, and connect more groups. One of the emerging issues was that 'women's access to IT also seems to be a major hindrance'. Other examples are drawn from the responses of women researchers (mostly from the Association of African Women for Research and Development, AAWORD), who complained that only secretaries had access to the computers in their departments. They did not have decision-making powers in determining how computers should be used, or where modems should be installed. If women at this high-level had these problems, what about the poor? Other initiatives outlined are the APC Women's networking programmes, the Women's Environment and Development Network (WEDNET) research project, and the building of a women's information and communication network in South Africa on SangoNet.

\section{Challenges in adopting IT in developing countries}

By its very nature the IT phenomenon is relatively in the developing world. Available data, suggest that the majority of developing countries such as Kenya in sub-Saharan Africa are lagging behind in the information revolution (Zhao and Frank, 2003). Not surprisingly, the quest for adoption of IT in educational management has been problematic and will require fundamental shifts in the regulatory environment, as well as renewed attention to public-private partnerships and social services. For example, developed countries have 80 per cent of the world's Internet users, while the total international bandwidth for all of Africa is less than that of the city of São Paulo, Brazil (Campbell and Sellbum, 2002).

Yahya (1993) examined some of the problems facing efficient use of information technology in developing countries. "They result from, among other factors, the high costs of imported systems (both hardware and software), the lack of sufficiently trained personnel and deficiencies in the industrial infrastructure." (p. 349)

Furthermore, many African leaders are known for their unwillingness to spend on training of their people in new and emerging technologies, most of the IT trainings are done mainly by donor organizations who run businesses and research centers in developing countries. How can African countries then bridge the digital divide in IT? Not having a solid group of IT practitioners and educators can evidently hamper Africa's efforts in implementing and managing IT in DRC and in other parts of Africa.

Opoku-Mensah (2008) provides a partial explanation about the reasons that account for a limited pool of IT practitioners in Africa. She believes that there is a "lack of scientific capacity due to the limited number of trained scientists and researchers in the continent." She argues that "up to 50,000 African scientists with post- 
graduate qualifications work outside their mother continent." Motivo (2005) thinks that "retaining technologically literate staff is not easy in rural setting." (p.23). Unwin (2009) addresses the brain drain challenge in Africa. He argues: "Many developing countries get little return from their investment in higher education as too many graduates leave or fail to return home at the end of their studies. This leads to a dwindling professional sector that has a knock-on effect as institutions become increasingly dependent on foreign expertise (p. 207). Ayittey (1998) describes this dilemma clearly and tend to differ on how the resources are shared: "Due to the explosion in the number of satellite dishes, electronic communications (fax machines, the Internet, e-mail, etc.), much more information is available in Africa. The new technology has severely hindered the ability of African dictators to control the flow of information and keep their people in the dark. In their desperate attempts to retain control, defamation or libel suits, heavy fines, and murder have become the choice of corrupt regimes" (p. 232). This may explain why such most wealthy countries struggles to jumpstart its economic development.

\section{The digital divide}

The concept of "digital divide" refers precisely to the inequalities stemming from varying opportunities of access to and use of such technologies, which reflects the patterns of inequity that exist in society. New terms have emerged in that connection: the "techno rich" and the "techno poor". The former refers to those who have access to the infrastructure and education necessary to use ICTs productively. By contrast, the "techno poor" are those that for economic, educational, cultural and other reasons are excluded from their benefits.

That is why it is necessary to broaden knowledge about both the potential opportunities IT may give to countries and their actual impacts and manifestations in different contexts and social groups.

The number of Internet users throughout the world towards the end of 2002 was 591 million, according to the 2003 Report on E-business and Development at the United Nations Conference on Trade and Development. That same report indicates that in the 2001-2002 period the number of users in Latin America grew by 35.5\%. In actual figures, this meant going from 17.8 million in 2000 to 26.1 million in 2001 and 35.4 million in 2002.

\section{Other extension services}

There are a number of ICT-based initiatives which cater for non-market information and extension services including financial, utilization of best agriculture practices, research, weather, climate, and distribution and supply chain management. Some of the initiatives include: KenCall Farmers Helpline, Kilimo Salama, MPESA, and Mali Shambani - all in Kenya, Esoko, Cocoalink and Radio Ada in Ghana, and MAKWACHA in Malawi. KenCall Farmers Helpline, a for-profit call center in Kenya, is a real-time call center service staffed by agricultural experts that provide agricultural information, advice and support to smallholder farmers over the phone, using voice and voice call-back to farmers (Payne et.al., 2010a).

Mali Shambani, in Kenya, is a weekly hour-long radio program featuring agricultural news and responding to a wide range of topics, including market prices and trends, farming techniques, weather and seasonal issues, financing opportunities, inputs, land use, and quality standards. Each program also offers an interactive call-in component where farmers are given the opportunity to pose agricultural questions to a panel of experts either via phone or SMS. In addition, Farmer Voice Radio (FVR) is a radio extension service currently operating in Kenya, Malawi, Tanzania, Mali, Ghana and Zambia that targets smallholder farmers. Extension agents of FVR provide regular, on-site extension support to a small group of pre-selected farmers, which are then documented and broadcast via radio (Payne et. al., 2010a).

In Kenya and Malawi, e-banking and especially mobile banking is another ICT-based service which has had a tremendous impact on the socio-economic status of farmers. Through innovative schemes such as MPESA in Kenya, farmers are able to send and receive money using their mobile phones. Safaricom reported 6.18 million registered M-Pesa users as of March 2009 (ITU, 2010b). The smart-card-based MAKWACHA system in Malawi allows rural farmers to receive payments and purchase farm inputs electronically. The card can be used at any of the company's ATM terminals situated at merchant stores in rural trading centers throughout the country (Nyirenda-Jere, 2010). In Kenya, mobile telephony was being used for delivery of animal health services which has reduced transactions costs and increased efficiency of animal care (Kithuka, et al. 2007).

The system works with a community animal health worker, who purchases a veterinary drug kit and mobile phone at a subsidized price. Animal health assistants and veterinarians working with the project also receive mobile phones. The phone system allows the animal health care providers to update one another, share information, and conduct referrals. ICTs are also being used in distribution and supply chain management and traceability to increase efficiency and predictability and to reduce spoilage (including recording movements along the value chain, responding to quality standard requirements, and helping large buyers track, manage, pay, and reward small producers). Examples include: dairy sector and agribusiness in Kenya; cotton supply system in Zambia; fruit and vegetable supply system in Mali and Ghana (Payne et. al., 2010b; Action for Enterprise and Payne, 2010). 


\section{The Study}

Current marketing and sales practice and theory are undergoing unprecedented transformations that may be highly attributed to the adoption of new technology tools and marketing concepts, such as relationship marketing, sales force automation tools, database marketing, electronic trading systems, network marketing, and, finally, the Internet. Transferring the thought of the Harvard Business School marketing theorists, the main thrust of the transformation in marketing practice could be reduced to the shift from broadcast marketing to interactive marketing that introduces marketing concepts and practices that are more customized and responsive to the individual. Deighton, John (1996). In this context, the Internet has been characterized as the ultimate interactive medium. IT has become the foundation of every sector of the economy, the reason are known from the studies that have been carried out an includes; reduced transaction costs through e-commerce thereby improving productivity, offer immediate connectivity including voice, data, visual which improves efficiency, transparency and accuracy. Increased choice in the marketplace and providing access to otherwise unavailable goods and services, it also widens the geographic scope of potential markets. These attributes shows the importance of IT in the growth of the economy in both developed and developing worlds. The above listed attributes are also critical to expanding individual economic opportunity, enabling people to enhance their skills and knowledge; identify, apply and qualify for better paying jobs and tap into broader markets for their goods and services.

In this context, the Internet's core advantage lies in its great capacity of fast, efficient, integrated, and interactive exchange of information. The multiple tools of the Internet enable the transmission and exchange of information through multiple formats, namely one-to-one communication (i.e., through e-mail), one-to-many (i.e., through the Web or e-mail), and many-to-many (i.e., through the Web, newsgroups and mailing lists) communication. Thus, the Internet facilitates the information exchanges between organizations, concerning issues such as discovery of new customer needs, trends of the local and global markets, competitive moves, joint development of products, joint selling activities, etc. Porter, Michael, and Victor, Millar (2001). Similarly, Cunningham and Tynan (2000) sustain that electronic technologies (i.e., the Internet) should be seen as a key part of the corporate strategies of business in the 2000 and beyond. According to Blattberg and Deighton (2001), we are running the age of addressability, in which the enhanced capabilities of improved and interactive communication imply new marketing opportunities and trends, such as database marketing, micromarketing, and integration of marketing activities. Moreover, the Internet is going to lead companies to even finer market segmentation. In a similar context, the attributes of the new IT, (i.e., the Internet), will lead to new marketing paradigms of microsegmentation and targeting in niche markets, which have been characterized as monocasting and point casting marketing (1999). Thus, Armstrong and Hagel (2002) note that "marketers will then (when they will be fully exploiting virtual markets such as the market that can be developed through the Internet) need to wrestle with microsegmentation not just at the level of the individual customer, but at the level of the individual customer at specific points in time." Furthermore, the Internet may facilitate the interactive communication between salespeople and their markets, by providing them with new capabilities, such as access to distant databases through on-line connection, performance of audiovisual presentations, and efficient transmission of electronic catalogues and infomercials. Thus, it is hypothesized:

The greater the use of the Internet tools, the larger the impact on sales management activities, involving market segmentation and customer classification, managing customer databases, sending electronic catalogues to the customers, and making audiovisual presentations. With this background on the benefits of IT, the hypotheses should be very clear that it's not an option to ignore technology at any point in time and this should be able to push governments, stakeholders, academicians and donors to promote the use of internet technology at all levels of productivity as this will improve the economy of the country and individual busienesses.

\section{The Results}

\section{Average number of the clients served in a day before and after adoption of IT.}

This section sought to assess the Average number of the clients served in a day before adoption of IT. From figure below $57.5 \%$ of the respondents revealed that the average number of clients served in a day before adoption of IT were between $0-10$ which was relatively low, whereas $17.2 \%$ of the respondents revealed that they served between 11-20 clients. In addition, $13.8 \%$ said they served between $21-30$ clients, $6.9 \%$ and $4.6 \%$ of the respondents said that they served between $31-40$ and 40 and above clients respectively. The study revealed that IT increased the number of daily clients thus increasing sales. The study established that the average service rate before adoption of IT in the organization was very low comparing with average number of clients served in a day after adoption of IT. Therefore IT is of great importance in any organization. 


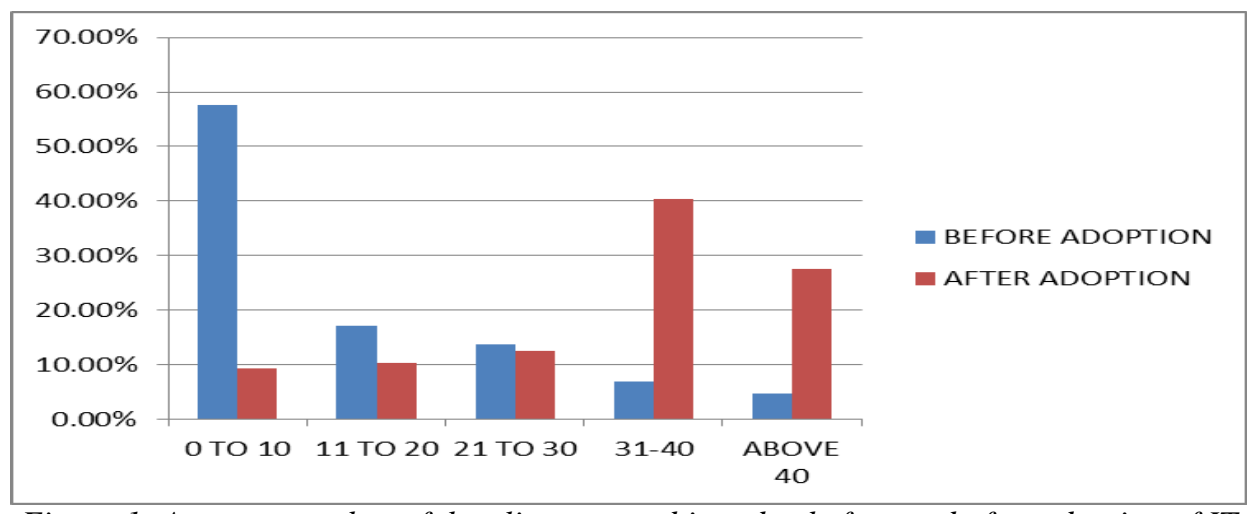

Figure 1: Average number of the clients served in a day before and after adoption of IT

\section{A Critique: Reasons for the Failure of ITs Initiatives}

Based on several analyses, it has been found that a variety of factors contribute to the stagnation of many IT projects in Development Countries. These factors are: attitude, accessibility, poor policies, inadequate skills and poor infrastructure. They are discussed briefly below:

\section{Main constraints}

Majority of the respondents felt that the main constraints to adopting Internet technology is lack of inadequate infrastructure $34 \%$ while $21 \%$ felt that it was because of lack of skills. Only $10.3 \%$ indicated that the main constraints to adopting Internet technology were because of attitude and $12 \%$ felt that there are no proper policies in place to govern the use and implantation of IT. $23 \%$ of the respondents felt that accessibility is the major constraint to adopting IT.

The level of affordable access to IT infrastructure should be such that all who wish to communicate and to use accessible information can use it as needed to add some value to their activities. While the Caribbean infrastructure is relatively sound, it is expensive and not universally networked or distributed across the communities in the region.

In CARICOM member states, main line telephone penetration, an index for measuring the degree of development of telecommunications infrastructures, ranges from a high of $60 \%$ in St. Kitts \& Nevis to a low of $1.7 \%$ in Haiti. The average main line telephone penetration in CARICOM at the end of 2005 was just over $10 \%$ compared with over 60\% in North America (Canada and USA). In Kisumu municipality, the scenario is not different, accessibility takes $23 \%$ which shows that many users of internet still find it hard to get access to the facility. Examples include: the length of time the community has been exposed to ITs; the type of industry(ies) in, and the socioeconomic structure of, the area; and how businesses view the use of ITs in relation to their operations. By overlooking such contextual considerations, the advocates of IT projects can mis-specify and under-resource the social and human infrastructure required. It is necessary that citizens are able to not only access that technology but that they also possess the skills to use and the resources to access them. This endeavor might require governments and communities employing skilled specialists in regional areas (Simpson and Hunter, 2001) [23]. As a number of Kenyan and international initiatives have indicated, relying on volunteers to raise awareness and to provide training can be detrimental to the sustainability of a project in that, where there is only a small pool of volunteers to draw upon, these people may suffer from burnout (Colle, 2000) [7].

Attitude- CBOs' computer experience relates positively to their computer attitudes. The more experience users have with computers, the more likely that they will show positive attitudes towards computers (Rozell \& Gardner, 1999). Positive computer attitudes are expected to foster computer integration in the office and home (van Braak, Tondeur \& Valcke, 2004). According to (Woodrow, 1992) for successful transformation in educational practice, user need to develop positive attitudes toward the innovation.

Skills- This issue is particularly important because it impacts not just managers and end-users, but the IT professionals as well. Levels of individual expertise range widely across organizations. The ramifications of this problem are deceptive, often the assumptions are that this is merely an issue surrounding the training of users and managers on new ITs and their applications. This is not the case. When planning for ITs, it is important to consider the expertise levels of all individuals throughout the organization and what needs should be addressed based on those levels. A secondary impact which this issue has on planning is the difficulties which arise based on the expertise levels of those engaged in the process itself. In other words, it is very difficult to plan effectively for ITs if your understanding of them is limited. 
Infrastructure- One of the top issues of obvious import to this particular area was insufficient infrastructure plan for internet technology. As discussed in chapter 4 above, 34\% of the respondents perceived this issue as highly problematic. As might be expected, the lack of a formalized strategic plan for IT makes the planning process more problematic. The key here is the formalized nature of the plan that shows the infrastructure in terms of availability, cabling, telecommunications lines. Lack of infrastructure plan or use of a purely informal plan provides little or no concrete directives for the acquisition or implementation of iternet technologies within an organization.

Accessibility- Access to IT infrastructure and resources in organizations is a necessary condition to the integration of IT in education (Plomp, Anderson, Law, \& Quale, 2009). Effective adoption and integration of IT into organizations depends mainly on the availability and accessibility of IT resources such as hardware, software, etc. Obviously, if users cannot access IT resources, then they will not use them. Therefore, access to computers, updated software and hardware are key elements to successful adoption and integration of technology. A study by Yildrim (2007) found that access to technological resources is one of the effective ways to users' pedagogical use of IT in their operations.

The multiplicity factors in the productivity of IT is apparent when examining specific cases. These examples indicate that there is significant variation in mechanisms of how ITs might yield productivity gains (Lennie et al., (2002 [18]). The use of ITs within an enterprise or small scale producers could either enhance or reduce productivity through their effect on at least three functions and processes.

First, distributed systems, intranets and web band services all change the logic of space and time that connects initiatives to their stakeholders. However, the opposite is also true. For example, where banks have replaced branches with ATMs in Kenya, their managers appear to have failed to understand their customers' attachment to real rather than virtual branches (Hearn and Manderville, 2004 [15]), in this case the managers may not understand the real issues affecting their customers. New markets and users can clearly be reached.

Second, they might reduce the informational component of an enterprise's transaction costs. Alternatively, ITs may increase transaction costs by adding additional steps in the production process through increases in the level of technology and/or staff needed to process logistical information. ITs might also expand the amount of information that has to be collected. There are also significant hidden human resource costs in terms of training and recruitment (Hearn and Manderville, 2004 [15]). There by increasing the production costs.

\section{Difference the use of Internet Technology has made with regard/Personal growth and development}

This section sought to determine the Difference the use of Internet Technology has made with regard to Personal growth and development. The results of this section were as shown below;

Table 1 Areas where IT has made a difference

\begin{tabular}{|l|r|r|}
\hline AREA THE DIFFERENCE IS EXPERIENCED & FREQUENCY & \multicolumn{1}{|c|}{ PERCENTAGE } \\
\hline Jobs creation & 22 & $34 \%$ \\
\hline Research & 9 & $14 \%$ \\
\hline Empowerment Skills & 15 & $23 \%$ \\
\hline Improved productivity & 15 & $15 \%$ \\
\hline All the above & 9 & $14 \%$ \\
\hline TOTAL & $\mathbf{6 5}$ & $\mathbf{1 0 0 . 0 \%}$ \\
\hline
\end{tabular}

\section{Areas IT has made impact}

From the figure 16 above, $33.8 \%$ of the respondents concurred that IT has made a difference in their lives in the various areas mentioned above. $15.4 \%$ of the respondents were able to compare jobs online while $13.8 \%$ of the respondents admitted that they were able to conduct research through IT where as $23.1 \%$ concurred that their empowerment skills improved and $13.8 \%$ of the respondents admitted that their productivity also improved.

A survey conducted on the role IT sector in economic development in Pakistan on employment creation in developing countries has been widely recognized and studied extensively at regional and international levels Kenny, C. (2002). The studies have concluded that IT adoption contributes to productivity and increases total factor productivity in economic growth, and that the creation of an enabling environment for domestic IT uptake, has sustained strong growth in some developing and transition countries. Through the establishment of rural information centres, ICTs can create employment opportunities in rural areas by engaging digital hub managers, subject matter specialists, information managers, translators and information technology technicians. Such hubs can help bridge the gap between urban and rural communities and reduce the rural-urban migration problem. 
The CRNM report (2006) which was done in respect of WTO market access issues related to telecommunications services, underscores the role of computers in facilitating digital convergence of information and communications, using devices like Internet, and the countless innovative applications able to run through these delivery channels, the report concludes that most developing countries focus on basic application on marketing and not other applications like job comparison, research and even communication.

ITs can empower rural communities and give them "a voice" that permits them to contribute to the development process.

With new ITs, rural communities can acquire the capacity to improve their living conditions and become motivated through training and dialogue with others to a level where they make decisions for their own development (Balit,2004) [3] . Giving rural people a voice means giving them a seat at the table to express their views and opinions and becoming part of the decision-making process. The approach should be participatory and could lead to improved policy formation and execution. Improved policy formulation and strategies, however, require "an educated and informed populace to reduce poverty, excessive population growth, environmental degradation and other factors that are most often the direct causes of hunger" (FAO, 1998)[10]. The chart below shows the benefits discussed above.

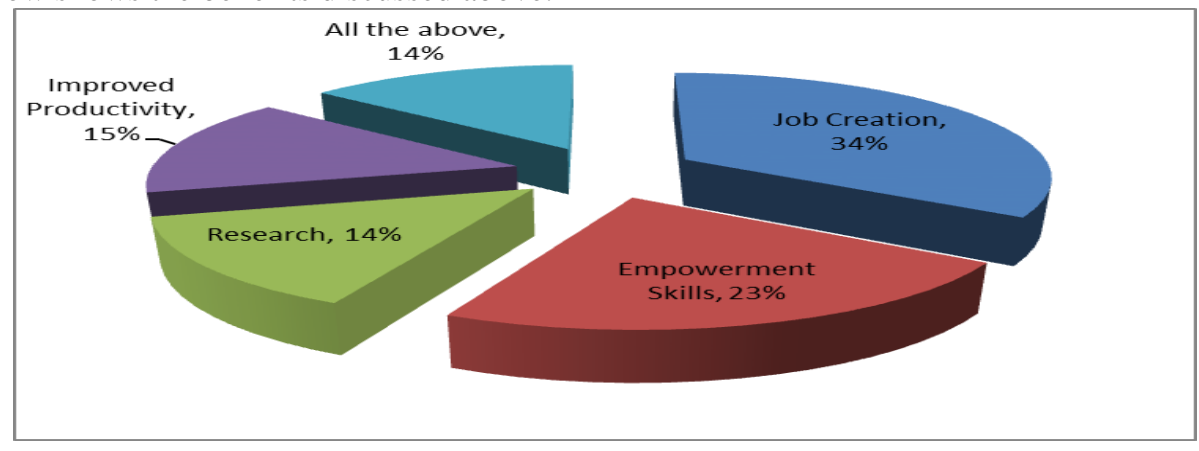

\section{Conclusion}

The respondents' business organizations were mostly for goods and services. The study revealed that the average number of clients served in a day after adoption of IT were many as compared with the average number of clients served in a day before adoption of IT. On service rate before adoption of IT in the organization, the rate was very low comparing with rate after adoption of IT'. Further, the study revealed that IT increased the number of daily clients thus increasing sales and also the production rate in an 8hr working day after adoption of IT.

Majority of the respondents felt that the main constraint to adopting Internet technology is lack of resources and poor policies. The finding of this study was that the organizations suffered from lack of enough recourses and proper policies to adopt and implement IT.

The researcher further concluded that internet technologies adopted by these groups complimented each other for effective group performance. Many women led projects have started to use more sophisticated IT applications and hire more IT personnel leading to a higher IT adoption. Women led projects are changing their market from community to national to international as a result of increase in IT adoption level. There is an increase in the usage of IT for routine tasks and an increase in the level of trust for the reliability of IT systems in women led projects. The women population had increased in number and most of them were delegated duties related to the use or application of IT in their groups.

\section{Recommendations}

Marketing tools that have been deployed in Kenya especially in Kisumu, can be extracted from our literature review and they include;

- The Kenya Agricultural Commodity Exchange (KACE) has commodity exchange service through offers and bids, which are prominently displayed on blackboard and which are disseminated via SMS and Internet. KACE collects, updates, analyses and provides reliable and timely market information and intelligence on a wide range of crop and livestock commodities, targeting actors in commodity value chains, with particular attention to smallholder farmers and small scale agribusinesses (KACE, 2011)

- There are a number of IT-based initiatives which cater for non-market information and extension services including financial, utilization of best agriculture practices, research, weather, climate, and distribution and supply chain management. Some of the initiatives include: KenCall Farmers Helpline, Kilimo Salama, MPESA, and Mali Shambani - all in Kenya. KenCall Farmers Helpline, a for-profit call center in Kenya, is a real-time call center service staffed by agricultural experts that provide agricultural information, advice and 
support to smallholder farmers over the phone, using voice and voice call-back to farmers (Payne et.al., 2010a).

- In Kenya, e-banking and especially mobile banking is another IT-based service which has had a tremendous impact on the socio-economic status of farmers. Through innovative schemes such as M-PESA in Kenya, farmers are able to send and receive money using their mobile phones. Safaricom reported 6.18 million registered M-PESA users as of March 2009 (ITU, 2010b).

All these have been able to support the farmers especially under e-commerce where they have been able to buy and sell online, but this is limited to the provider but no tool is used to market these goods and services for the farmer online. From the findings, the researcher appreciates the role internet marketing is playing on the productivity of women led projects.

The researcher proposes;

- Web Based Touchscreen Tool; The design and implementation of web-based touch screen tool that will help jubilee market traders market their products internationally and even locally. According to PC Magazine a touch screen is, "a display screen that is sensitive to the touch of a finger or stylus. Widely used on ATM machines, retail point-of-sale terminals, car navigation systems, medical monitors and industrial control panels, the touch screen became wildly popular on handhelds after Apple introduced the iPhone in 2007." The touch screen is one of the easiest to use and most intuitive of all computer interfaces, a touch screen allows users to navigate a computer system by touching icons or links on the screen.

- Digital hubs; The design and implementation of digital hubs that should be mounted in different communities that will help the farmers to;

- To promote and sustain community based livelihood entrepreneurship skills development program though ICT.

- To research and compare the felt needs of the products from different communities across the globe and identify those that can be satisfied with acquisition of information and knowledge.

- To encourage participation of community to engage in national and international events like the International Agricultural Day and other events through on -line tools like cyber dialogues.

- To explore use of information technology to promote social networks and entrepreneurship among the women. This will involve promoting use of social media to mobilise and engage with women population especially in the Rural setting.

- Website design and development of websites for local entrepreneurs and publishing on local intranet for community use

- To mobilise the women to participate in social media dialogue and empower them to make informed decisions.

- Capacity-building and training: One major constraint to the delivery of ITs initiatives in rural areas is weak institutional capacity and insufficient coordination. Government, NGOs and the private sector in particular possess a vast but often untapped potential. Women managers could seek partners to fund capacity-building activities. The partnership could also assist with building the required human and institutional capacities at national and regional levels to provide training and education to rural communities on how to manage local knowledge and information, using ITs. The training materials produced could be availed as an electronic archive of training resources, and could be repackaged in preferred media such as the successful video-based model used in low developing countries. The resources could then be translated into major languages to ensure that most developing countries benefit.

\section{Map of Kisumu Municipality showing informal settlements}




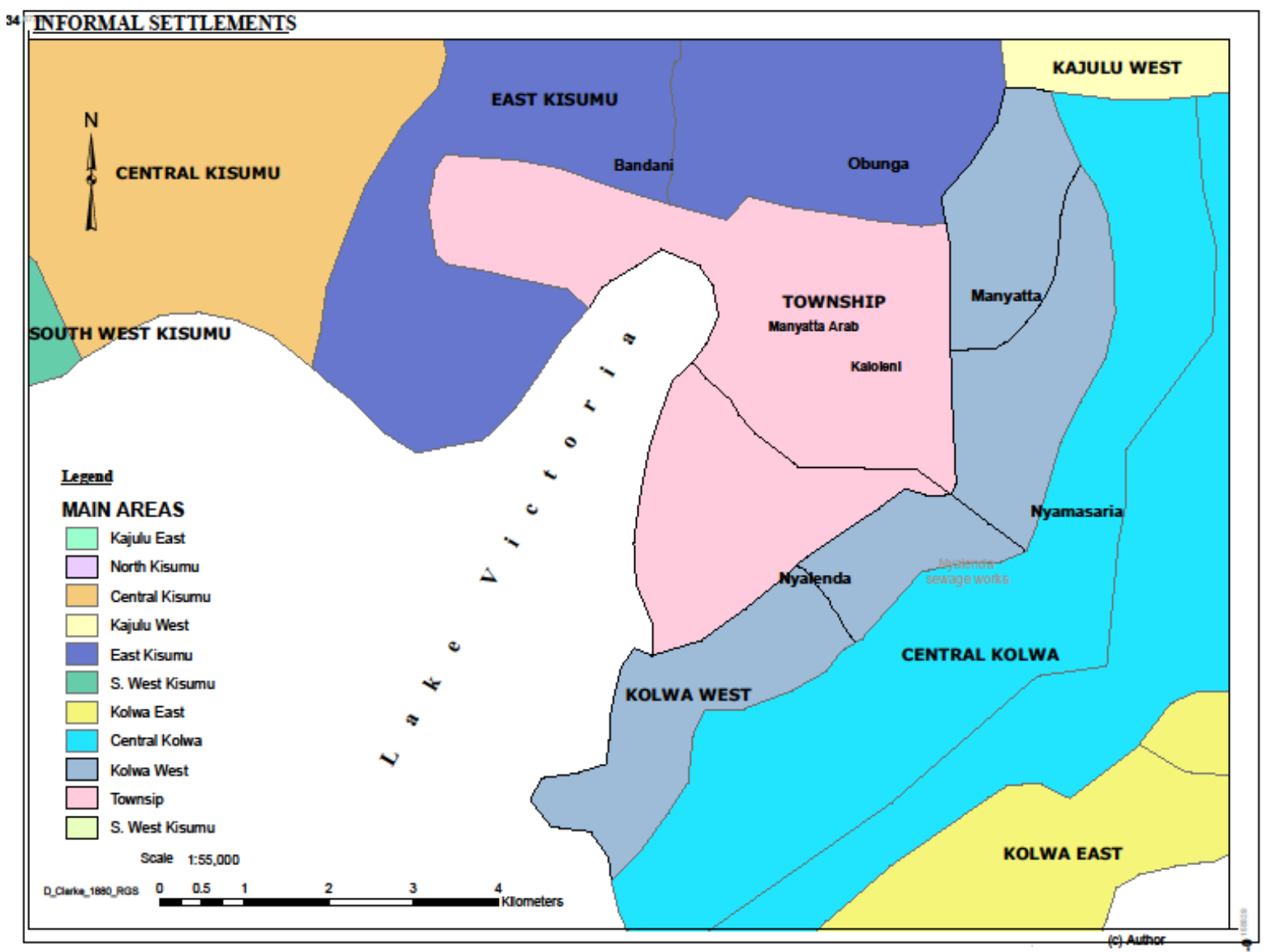

Plate of Jubilee Market

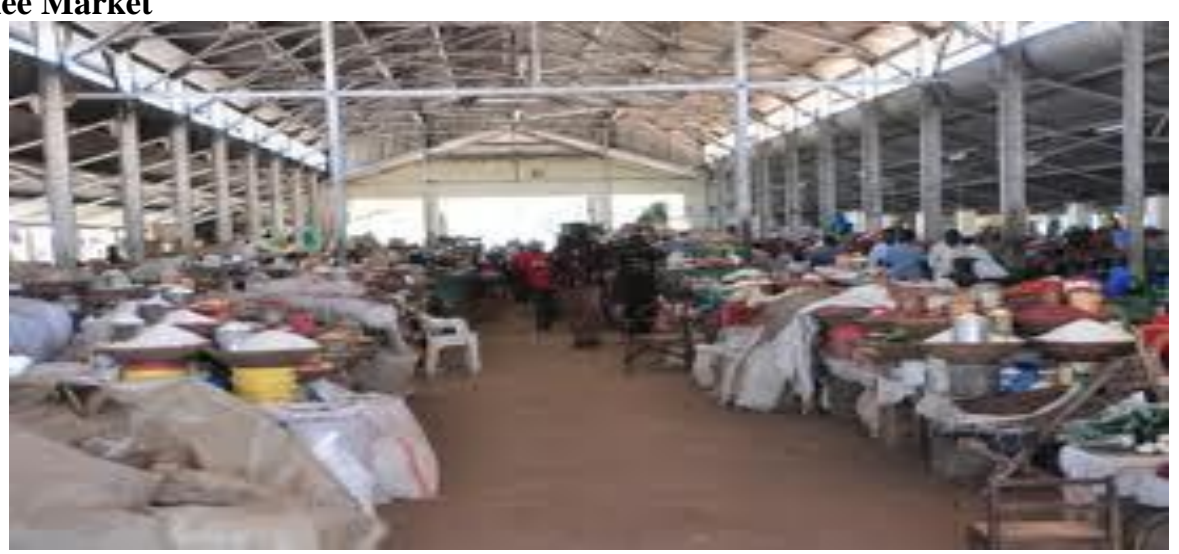

\section{References}

[1]. Ayittey, George B.N. (1998) Africa In Chaos. New York: St. Martin's Press,.

[2]. Dedrick, J., Gurbaxani, V. \& Kraemer, K. L. (2003). Information technology and economic performance: a critical review of the empirical evidence. ACM Computing Surveys, 35(1), 1-28.

[3]. Deighton, J. A.(1992). "The Consumption of Performance." Journal of Consumer Research 19 362-72.

[4]. Demiryürek K. (2008): The use of social network analysis (SNA) to identify opinion leaders: the case of organic hazelnut producers in Turkey. Journal of Extension Systems, 24: 17-30.

[5]. Gilchrist, A., Green, J., Cox, A., Burton, D., Rutter, M., \& Le Couteur, A. (2001). Development and current functioning in adolescents with Asperger syndrome: A comparative study. Journal of Child Psychology Psychiatry, 42, 227-240.

[6]. Kagira J.M., Kanyari P.W.N. (2001). The role of parasitic diseases in causing mortalities in small ruminants in a highly productive area of Central Province, Kenya. J. S. Afr. Vet. Assoc. 72:147 149.

[7]. Kuppusamy M. and Santhapparathy, S. A., (2005). Investment in information and communication technologies (ict) and its payoff in Malaysia. Perspectives on Global Development and Challenges in Implementing a NICT Plan in the Congo 21 Technology, 4(2), 147-167. Koninklijke Brill NV, Leiden. Retrieved September 10, 2009.

[8]. Thilmany, Dawn D., Jennifer Keeling Bond, Craig A. Bond, Cecil Stushnoff, Frank Stonaker, Patricia Kendall, and Marisa Bunning. (2006). Eat Your Fruits and Veggies: Exploring Fresh Produce Market Choices. Food Distribution Research Society Conference Proceedings 37(1). 
[9]. Torero,Maximo and Joachim Von Braun (eds.) (2006): Information and Communication Technologies for Development and Poverty Reduction. The Potential of Telecommunications. Baltimore, MA, USA: The Johns Hopkins University Press for the International Food Policy Research Institute (IFPRI), Washington, DC, USA, 392 pp.

[10]. Wagner, M., Kutash, K., Duchnowski, A. J., \& Epstein, M. H. (2005a). Th e Special Education Elementary Longitudinal Study and the National Longitudinal Transition Study: Study designs with implications for childrenand youth with emotional disturbance. Journal of Emotional and Behavioral Disorders, 13(1), 25-41.

[11]. Zhao, Y. and Frank, KA (2003). Factors Affecting Technology Uses in Schools: An Ecological Perspective [Electronic Version]. American Educational Research Journal, 40(4), 807-840. 